\title{
Numerical investigation of sensible thermal energy storage in high temperature solar systems
}

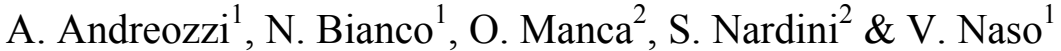 \\ ${ }^{1}$ DETEC - Università degli Studi di Napoli Federico II, Italy \\ ${ }^{2}$ DIAM - Seconda Università degli Studi di Napoli, Aversa (CE), Italy
}

\begin{abstract}
A study on sensible thermal energy storage (TES) for high temperature solar systems is numerically accomplished. The high temperature TES is cylindrical, the fluid and the solid thermo-physical properties are temperature independent and the radiation heat transfer mechanism is neglected. A parametric analysis is carried out. The commercial CFD Fluent code is used to solve the governing equations in the transient regime. Numerical simulations are carried out at different mass velocity values of the heat-carrying fluid and porosity of the storage medium. The results show the effects of the porosity and of the working fluid mass velocity on the stored thermal energy and on the storage time.
\end{abstract}

Keywords: solar energy, sensible thermal energy storage, numerical analysis.

\section{Introduction}

Thermal energy storages (TESs) are employed in many solar thermal plants in order to ensure the continuity in energy supply and minimize instability. Moreover, the use of TES for thermal applications, such as space and water heating, cooling and air-conditioning, has recently received attention [1-4]. The storage purpose is twofold: to increase the value of the power generated by strongly reducing its randomness and to improve the plant economics by using the available hardware for more hours a year. Recent concentrating solar plant projects incorporate heat storage that allows the system to operate for some 6-12 hours in the absence of solar irradiance [5]. 
Three types of TES systems are, generally, employed in high temperature applications: latent heat storage systems, molten salt storage systems and sensible heat storage systems. Cost effective systems demand the utilisation of inexpensive storage materials, which usually exhibit a low thermal conductivity. Essential for the successful development of a storage system is the sufficient heat transfer between the fluid and the storage material. Recently, a high temperature TES was studied by a lab-scale cylindrical storage tank experiment [6]. A heat exchanger of TES was used for separating two fluids: the storage medium and the heat transfer fluid. A multi-tank sensible-heat storage system for storing thermal energy, with a two-tanks molten salt system, was proposed in [7].

In a high concentrating solar receiver, the temperature reaches values in the range from $800{ }^{\circ} \mathrm{C}$ to $1800^{\circ} \mathrm{C}$ and the fluid employed in the plant is often a gas, such as air. In air based solar energy utilization systems, storage of hot air is not possible due its low density. A denser medium is required for storage of thermal energy. In sensible TES, energy is stored by changing the temperature of a storage medium, such as water, oil, rock beds, bricks, sand or soil. The amount of energy input to TES by a sensible heat device is proportional to the difference between the final and initial temperatures of the storage medium, its mass and its specific heat. Each medium has its own advantages and disadvantages. Packed bed generally represents the most suitable energy storage unit for air based solar energy systems as mentioned in [8]. An extensive literature review of research work was presented in $[9,10]$ and, more recently, in $[11,12]$.

Several investigations on fixed bed energy storage use the model originally developed by Schumann [13]. This is a one dimensional two-phase transient model that enables the prediction of the axial and temporal distribution of the solid and fluid temperatures. Experiments using steel spheres to determine the heat transfer coefficient between the fluid and solid for air as the working fluid were accomplished in [14]. A modified version of Schumann's model was employed in [15] to solve the model equations using gas as the working fluid. A model with the fixed bed divided into two regions, one near the wall with high void fraction and the other in the bed central region was studied in [16]. The results and method given in [15] were employed in [16] to evaluate the temperature distribution and in [17] to verify high computational times when the ratio of the specific heat of the solid to the specific heat of the fluid was high. Investigations concerning the effects of the radial and axial dispersion in the bed were presented in $[18,19]$. How a single phase model can be derived from the continuous solid phase model was demonstrated in [20]. A storage unit of the fixed type using Schumann's model, including possible variations in the fluid inlet temperature, was modelled in [21].

It was found that the optimization of the packed bed design should aim at maximizing the ratio of total energy availability to total pumping energy, which increases when the size of the material elements increases [22]. However, thermal performance of the system may deteriorate due to the smaller area of contact available for heat transfer [23].

A numerical study on packed bed thermal models, suitable for sensible and latent heat thermal storage systems, was accomplished in [11]. An experimental 
investigation on the effect of the system and operating parameters on heat transfer and the pressure drop characteristics of a packed bed solar energy storage system with large sized elements of storage material was conducted in [12]. Solid media sensible heat storage materials were investigated in the experimental study reported in [24]. A thermodynamic procedure to analyze the energy and exergy balances of a rock bed thermal storage system was presented in [25]. A numerical investigation on the sensitivity of the long-term performance simulations of solar energy systems to the degree of stratification in both liquid and packed bed storage units was carried out in [26].

In this paper a high temperature sensible TES is numerically analyzed and a parametric analysis is accomplished. In the formulation of the model it is assumed that the system geometry is cylindrical, the fluid and the solid thermophysical properties are temperature independent, and the radiation heat transfer mechanism is neglected. The commercial CFD Fluent code is used to solve the governing equations in the transient regime. Numerical simulations are carried out at different mass velocities of the heat-carrying fluid and porosity of the storage medium. The results show the effects of the porosity and of the working fluid mass velocity on the stored thermal energy and on the storage time.

\section{Mathematical description and numerical procedure}

The proposed prototype of high temperature sensible TES is a cylinder whose diameter is equal to $0.60 \mathrm{~m}$ and height is equal to $1.0 \mathrm{~m}$. The storage material is steel and it is assumed to be a porous medium. The heat-carrying fluid is air. The thermo-physical properties of the steel and the air, reported in Tables 1 and 2, are temperature independent. The radiation heat transfer mechanism is neglected.

Table 1: $\quad$ Steel thermo-physical properties.

\begin{tabular}{|l|l|}
\hline Property & \\
\hline$c[\mathrm{~J} / \mathrm{kg} \mathrm{K}]$ & 502.48 \\
\hline$\rho\left[\mathrm{kg} / \mathrm{m}^{3}\right]$ & 8030 \\
\hline$k[\mathrm{~W} / \mathrm{m} \mathrm{K}]$ & 16.27 \\
\hline
\end{tabular}

Table 2: $\quad$ Air thermo-physical properties.

\begin{tabular}{|l|l|}
\hline Property & \\
\hline$c[\mathrm{~J} / \mathrm{kg} \mathrm{K}]$ & 1006.43 \\
\hline$\rho\left[\mathrm{kg} / \mathrm{m}^{3}\right]$ & 1.225 \\
\hline$k[\mathrm{~W} / \mathrm{m} \mathrm{K}]$ & 0.0242 \\
\hline
\end{tabular}




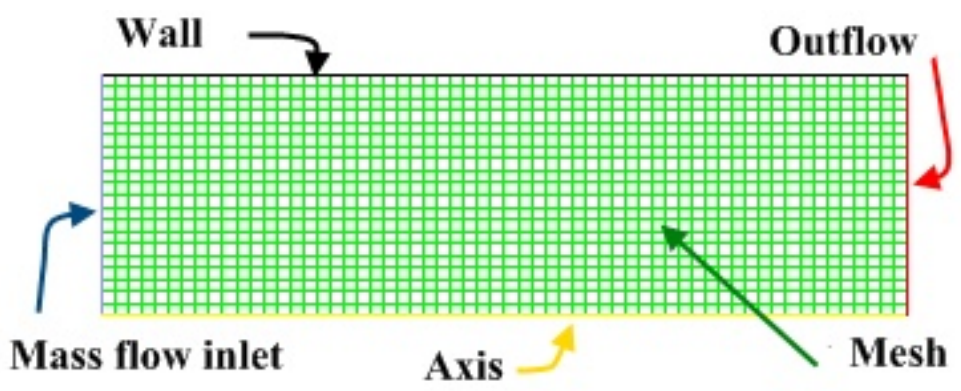

Figure 1: Computational domain with imposed boundary conditions.

Thanks to the axisymmetry of the physical model, a two-dimensional analysis was carried out. The employed computational domain is sketched in Fig.1, where the imposed boundary conditions are reported.

The temperature of the hot air entering the channel, $T_{i n}$, is equal to $1473 \mathrm{~K}$.

The commercial CFD code Fluent [27] was employed to solve the governing equations in transient and laminar regime. A rectangular shape mesh with 76800 cells has been employed. The initial temperature of the solid elements and of the heat-carrying fluid is assumed to be equal to $1073 \mathrm{~K}$. Air is the heat-carrying fluid, that is assumed to be an incompressible ideal gas.

Numerical simulations are carried out for different mass velocity values. The mass velocity, $G$, is the ratio of the module mass flow rate, $\dot{m}$, to the free flow area of the storage module cross section $S$, that can be expressed as the product of the frontal area of the module and its porosity

$$
G=\frac{\dot{m}}{S}
$$

For assigned $G$, different porosity values were considered. Results are given in terms of stored thermal energy in porous medium after the considered time interval, $Q_{\text {stored, }}$, as a function of time. The stored thermal energy is evaluated as

$$
Q_{\text {stored }}=\rho_{\text {eff }} c_{e f f}\left[\int_{V} \bar{T} d V-T_{i} V\right]
$$

where $V=0.283 \mathrm{~m}^{3}$ and $T_{i}=1073 \mathrm{~K} . \rho_{\text {eff }}$ and $c_{\text {eff }}$ are evaluated by:

$$
\rho_{\text {eff }}=\varepsilon \rho_{f}+(1-\varepsilon) \rho_{s} ; \quad c_{e f f}=\varepsilon c_{f}+(1-\varepsilon) c_{s}
$$

In Table 3, the effective density and specific heat values, evaluated for different porosity values, are reported. The viscous and inertial resistance coefficients, $1 / \alpha$ and $C_{2}$ respectively, depend on $G$ and $\varepsilon$. In Table 4 they are reported for different porosity values. 
A grid dependence analysis was obtained for $G=0.245 \mathrm{~kg} / \mathrm{m}^{2} \mathrm{~s}, T_{i}=1200 \mathrm{~K}$, $T_{a m b}=300 \mathrm{~K}, \varepsilon=0.40,1 / \alpha=6.00 \times 10^{5} \mathrm{~m}^{-2}$ and $C_{2}=1312.5 \mathrm{~m}^{-1}$. Six meshes were considered: $10 \times 30,20 \times 60,40 \times 120,80 \times 240,160 \times 480$ and $320 \times 960$. The comparison among results allows one to employ in the simulations the mesh 160 $\mathrm{x} 480$ as the more appropriate to obtain an adequate accuracy with a convenient computational time. A similar analysis was carried out also for different time steps. The most advantageous time step was equal to $5 \mathrm{~s}$.

The converging criteria were $10^{-3}$ for the residuals of the velocity components and $10^{-6}$ for the residuals of the energy.

Table 3: $\quad$ Effective density and specific heat of porous medium for different porosity values.

\begin{tabular}{|c|c|c|}
\hline$\varepsilon$ & $\rho_{\text {eff }}\left(\mathrm{kg} / \mathrm{m}^{3}\right)$ & $c_{\text {eff }}(\mathrm{J} / \mathrm{kg} \mathrm{K})$ \\
\hline 0.20 & 6424.20 & 603.27 \\
\hline 0.30 & 5621.30 & 653.60 \\
\hline 0.35 & 5219.93 & 678.86 \\
\hline 0.40 & 4818.49 & 729.18 \\
\hline 0.45 & 4417.05 & 725.25 \\
\hline 0.50 & 4015.61 & 754.45 \\
\hline 0.60 & 3212.70 & 804.85 \\
\hline
\end{tabular}

Table 4: Viscous and inertial resistance coefficients for different porosity values.

\begin{tabular}{|c|c|c|}
\hline$\varepsilon$ & $1 / \alpha\left(\mathrm{m}^{-2}\right)$ & $C_{2}\left(\mathrm{~m}^{-1}\right)$ \\
\hline 0.20 & 3846153 & 14000 \\
\hline 0.30 & 1307189 & 3629 \\
\hline 0.35 & 827814 & 2122.4 \\
\hline 0.40 & 600000 & 1312.5 \\
\hline 0.45 & 358551 & 845 \\
\hline 0.50 & 240030 & 280 \\
\hline 0.60 & 107526 & 259 \\
\hline
\end{tabular}




\section{Results and discussion}

Numerical simulations are carried out at the following mass velocity values: 0.20 $\mathrm{kg} / \mathrm{m}^{2} \mathrm{~s}, 0.30 \mathrm{~kg} / \mathrm{m}^{2} \mathrm{~s}$ and $0.40 \mathrm{~kg} / \mathrm{m}^{2} \mathrm{~s}$ and for an inlet temperature of the air equal to $1473 \mathrm{~K}$. The porosity $\varepsilon$ varies from 0.20 to 0.60 .

The stored thermal energy for a mass velocity value $G=0.20 \mathrm{~kg} / \mathrm{m}^{2} \mathrm{~s}$ and for different porosity values is reported in Fig.2. The profiles trends show that at initial time the stored energy is higher for the higher $\varepsilon$ value and they present an inversion at different time increasing the porosity value. Moreover, increasing the porosity determines a substantial decrease of the stored thermal energy in the long time. At each porosity the stored thermal energy reaches an asymptotic value, which indicates the thermal saturation of the reservoir. The time at which the thermal saturation is reached increases with decreasing porosity due to the increase in the thermal capacity of the reservoir. The lower thermal inertia causes a temperature increase in less time and a smaller thermal capacity, which determines the heat storage saturation in less time, too. The stored thermal energy values are reported in Table 5 for the first eight hours of computational simulation. The choice of this time period allows one to compare this values sequence with different porosity. For $\varepsilon \geq 0.45$ and after 4 hours, thermal energy stored reaches the $95 \%$ of the maximum stored thermal energy value, which is attained after 8 hours. Moreover, the previous observation is confirmed and the best condition for the thermal energy storage is that obtained for a porosity equal to 0.40 after three hours, with $\mathrm{Q}_{\text {stored }}=3.43 \times 10^{5} \mathrm{~kJ}$.

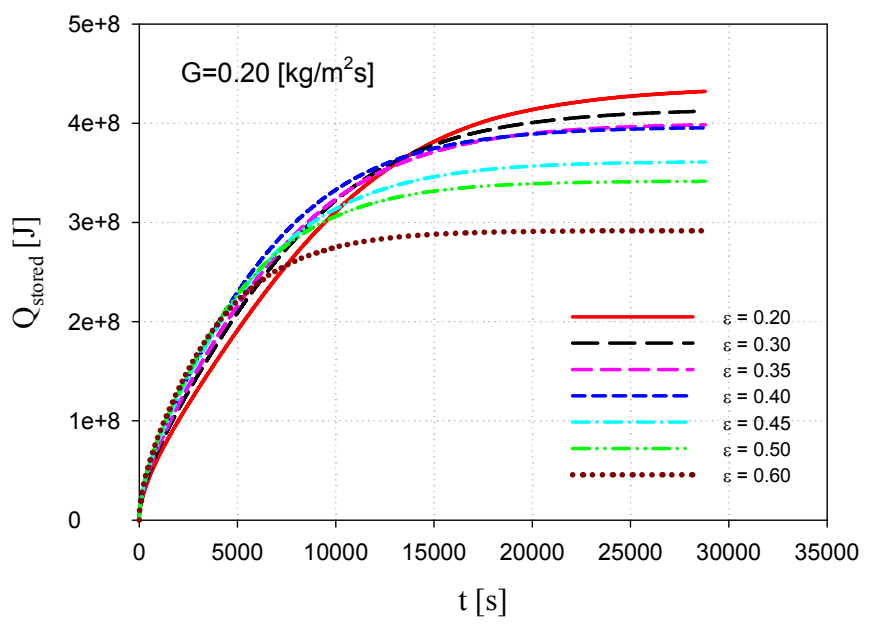

Figure 2: Stored thermal energy vs. time for $\mathrm{G}=0.20 \mathrm{~kg} / \mathrm{m}^{2} \mathrm{~s}$ and various porosity values. 
Table 5: Stored thermal energy values for the first eight hours of computational simulation and $\mathrm{G}=0.20 \mathrm{~kg} / \mathrm{m}^{2} \mathrm{~s}$.

\begin{tabular}{|c|c|c|c|c|}
\hline $\boldsymbol{\varepsilon}$ & $\begin{array}{c}\mathbf{Q}_{\text {stored }}[\mathbf{k J}] \\
\mathbf{3 6 0 0} \mathbf{~ s}\end{array}$ & $\begin{array}{c}\mathbf{Q}_{\text {stored }}[\mathbf{k J}] \\
\mathbf{7 2 0 0} \mathbf{~ s}\end{array}$ & $\begin{array}{c}\mathbf{Q}_{\text {stored }}[\mathbf{k J}] \\
\mathbf{1 0 8 0 0} \mathbf{~ s}\end{array}$ & $\begin{array}{c}\mathbf{Q}_{\text {stored }}[\mathbf{k J}] \\
\mathbf{1 4 4 0 0} \mathbf{~ s}\end{array}$ \\
\hline 0.20 & 150545 & 249630 & 325596 & 375233 \\
\hline 0.30 & 165968 & 266798 & 334424 & 373683 \\
\hline 0.35 & 172768 & 272400 & 334322 & 367535 \\
\hline 0.40 & 185031 & 285228 & 342594 & 371606 \\
\hline 0.45 & 182430 & 274022 & 321423 & 343735 \\
\hline 0.50 & 186881 & 272402 & 312521 & 329944 \\
\hline 0.60 & 187578 & 253941 & 278580 & 287312 \\
\hline $\boldsymbol{\varepsilon}$ & $\mathbf{Q}_{\text {stored }}[\mathbf{k J}]$ & $\mathbf{Q}_{\text {stored }}[\mathbf{k J}]$ & $\mathbf{Q}_{\text {stored }}[\mathbf{k J}]$ & $\mathbf{Q}_{\text {stored }}[\mathbf{k J}]$ \\
\hline 0.20 & 404451 & 419274 & 427647 & 432088 \\
\hline 0.30 & 394171 & 404327 & 409534 & 412137 \\
\hline 0.35 & 384404 & 392709 & 396618 & 398400 \\
\hline 0.40 & 384977 & 391266 & 394156 & 395447 \\
\hline 0.45 & 353897 & 358319 & 360177 & 360911 \\
\hline 0.50 & 337129 & 339952 & 341093 & 341539 \\
\hline 0.60 & 290290 & 291261 & 291579 & 291681 \\
\hline
\end{tabular}

Increasing the mass velocity value, $\mathrm{G}=0.30 \mathrm{~kg} / \mathrm{m}^{2} \mathrm{~s}$, in Fig. 3 , the differences with respect to the previous case are significant in terms of thermal saturation time. In fact, for this configuration, the profile of the stored thermal energy for a porosity value equal to 0.60 shows the asymptotic value after about $10000 \mathrm{~s}$ whereas in the first case this value was about $15000 \mathrm{~s}$. This is due to an increase in the convective heat transfer between the air and the porous medium. This is also evident in Table 6 where the stored thermal energy values are reported for the first eight hours of computational simulation. In this case for a porosity equal to 0.40 a $Q_{\text {stored }}=3.41 \times 10^{5} \mathrm{~kJ}$, very close to the previous value for $\mathrm{G}=0.20 \mathrm{~kg} / \mathrm{m}^{2} \mathrm{~s}$, is attained after 2 hours. It is about the $86 \%$ of the saturation value $\left(\mathrm{Q}_{\max }=3.96 \times 10^{5} \mathrm{~kJ}\right)$. Then the higher value of $\mathrm{G}$ determines a lower time needed to reach a good thermal storage level.

The variation in the stored thermal energy profiles is more marked when the mass velocity value is varied from $G=0.30 \mathrm{~kg} / \mathrm{m}^{2} \mathrm{~s}$ to $\mathrm{G}=0.40 \mathrm{~kg} / \mathrm{m}^{2} \mathrm{~s}$, as it is observed in Fig 4. For the lowest porosity values the profiles still show an increasing trend with higher stored thermal energy values, whereas for the higher porosity values a sudden increase in the thermal energy stored in the solid medium is observed. It is necessary to underline a progressive change in the material behaviour at increasing mass velocity values, the larger the porosity the larger the change. A reduction in the time necessary to reach the steady state, passing from about $10000 \mathrm{~s}$ for $\mathrm{G}=0.30 \mathrm{~kg} / \mathrm{m}^{2} \mathrm{~s}$ to about $7500 \mathrm{~s}$ for $\mathrm{G}=0.40$ $\mathrm{kg} / \mathrm{m}^{2} \mathrm{~s}$, at $\varepsilon=0.60$, is also observed, but with a considerable decrease in the inversion time. The value of this time between $\varepsilon=0.20$ and $\varepsilon=0.60$ changes 


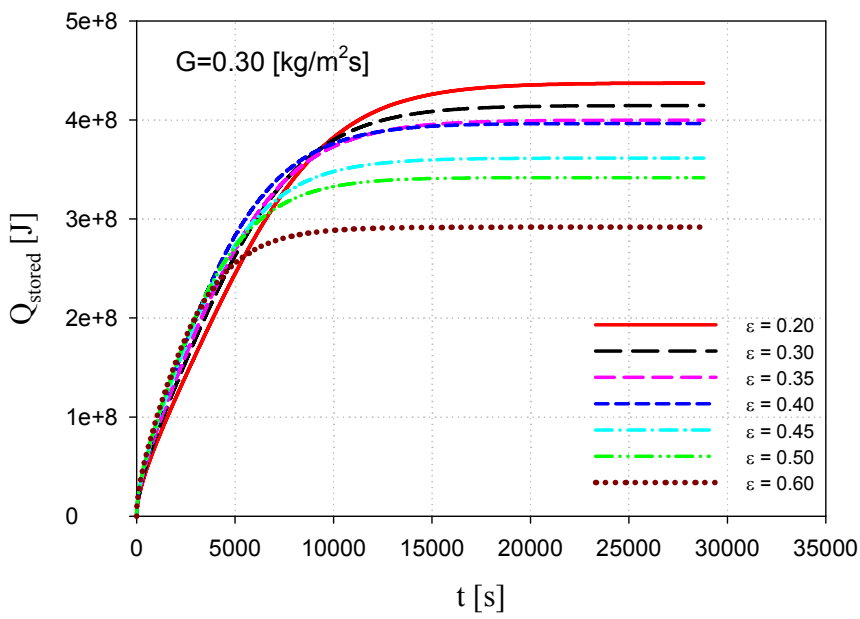

Figure 3: Stored thermal energy vs. time for $\mathrm{G}=0.30 \mathrm{~kg} / \mathrm{m}^{2} \mathrm{~s}$ and various porosity values.

Table 6: Stored thermal energy values for the first eight hours of computational simulation and $\mathrm{G}=0.30 \mathrm{~kg} / \mathrm{m}^{2} \mathrm{~s}$.

\begin{tabular}{|c|c|c|c|c|}
\hline $\boldsymbol{\varepsilon}$ & $\begin{array}{c}\mathbf{Q}_{\text {stored }}[\mathbf{k J}] \\
\mathbf{3 6 0 0} \mathbf{~ s}\end{array}$ & $\begin{array}{c}\mathbf{Q}_{\text {stored }}[\mathbf{k J}] \\
\mathbf{7 2 0 0} \mathbf{~ s}\end{array}$ & $\begin{array}{c}\mathbf{Q}_{\text {stored }}[\mathbf{1 0 J}] \\
\mathbf{1 0 8 0 0} \mathbf{~ s}\end{array}$ & $\begin{array}{c}\mathbf{Q}_{\text {stored }}[\mathbf{k J}] \\
\mathbf{1 4 4 0 0} \mathbf{~ s}\end{array}$ \\
\hline 0.20 & 188403 & 319531 & 393888 & 423381 \\
\hline 0.30 & 206097 & 330770 & 387898 & 407012 \\
\hline 0.35 & 213655 & 331778 & 379522 & 394244 \\
\hline 0.40 & 227702 & 340926 & 381475 & 392818 \\
\hline 0.45 & 223207 & 321104 & 351540 & 359157 \\
\hline 0.50 & 226780 & 312389 & 335368 & 340527 \\
\hline 0.60 & 222384 & 279047 & 289661 & 291420 \\
\hline $\boldsymbol{\varepsilon}$ & $\mathbf{Q}_{\text {stored }}[\mathbf{k J}]$ & $\mathbf{Q}_{\text {stored }}[\mathbf{k J}]$ & $\mathbf{Q}_{\text {stored }}[\mathbf{k J}]$ & $\mathbf{Q}_{\text {stored }}[\mathbf{k J}]$ \\
\hline 0.20 & 433180 & 436145 & 436926 & 437152 \\
\hline 0.30 & 412586 & 414029 & 414390 & 414483 \\
\hline 0.35 & 398396 & 399466 & 399721 & 399777 \\
\hline 0.40 & 395587 & 396218 & 396362 & 396393 \\
\hline 0.45 & 360943 & 361325 & 361401 & 361414 \\
\hline 0.50 & 341565 & 341757 & 341792 & 341798 \\
\hline 0.60 & 291684 & 291720 & 291725 & 291726 \\
\hline
\end{tabular}

from about $7000 \mathrm{~s}$ for $\mathrm{G}=0.20 \mathrm{~kg} / \mathrm{m}^{2} \mathrm{~s}$ to about $4000 \mathrm{~s}$ for $\mathrm{G}=0.40 \mathrm{~kg} / \mathrm{m}^{2} \mathrm{~s}$. For this configuration the best condition for the thermal energy storage is obtained for $\varepsilon=0.20$, as observed in Table 7 . In fact, after 2 hours the highest $\mathrm{Q}_{\text {stored }}$ value is equal to $3.76 \times 10^{5} \mathrm{~kJ}$ for $\varepsilon=0.20$ and it is about $86 \%$ of $\mathrm{Q}_{\max }$ at this porosity. 


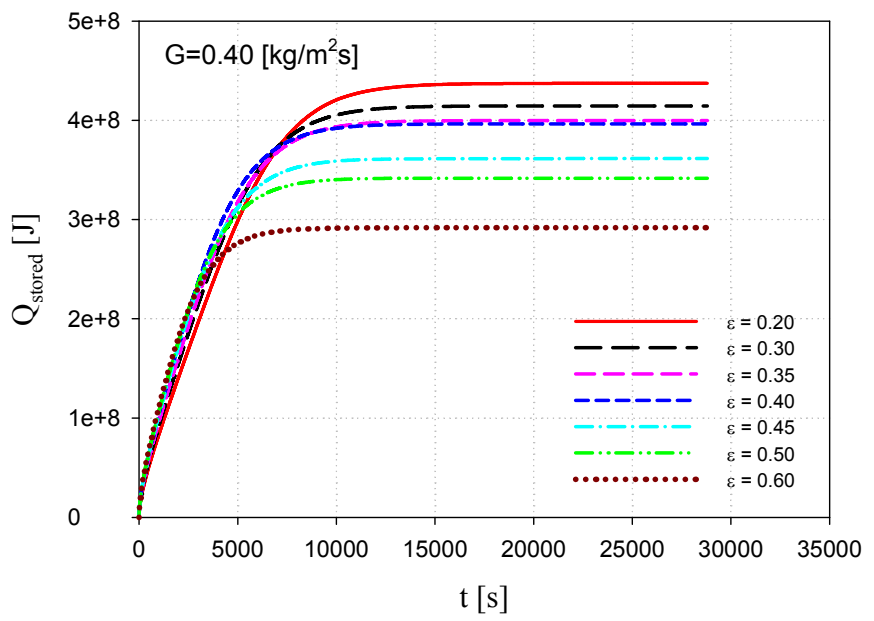

Figure 4: Stored thermal energy vs. time for $\mathrm{G}=0.40 \mathrm{~kg} / \mathrm{m}^{2} \mathrm{~s}$ and various porosity values.

Table 7: Stored thermal energy values for the first eight hours of computational simulation and $\mathrm{G}=0.40 \mathrm{~kg} / \mathrm{m}^{2} \mathrm{~s}$.

\begin{tabular}{|c|c|c|c|c|}
\hline $\boldsymbol{\varepsilon}$ & $\begin{array}{c}\mathbf{Q}_{\text {stored }}[\mathbf{k J}] \\
\mathbf{3 6 0 0} \mathbf{s}\end{array}$ & $\begin{array}{c}\mathbf{Q}_{\text {stored }}[\mathbf{k J}] \\
\mathbf{7 2 0 0} \mathbf{~ s}\end{array}$ & $\begin{array}{c}\mathbf{Q}_{\text {stored }}[\mathbf{k J}] \\
\mathbf{1 0 8 0 0} \mathbf{s}\end{array}$ & $\begin{array}{c}\mathbf{Q}_{\text {stored }}[\mathbf{k J}] \\
\mathbf{1 4 4 0 0} \mathbf{~ s}\end{array}$ \\
\hline 0.20 & 228993 & 376386 & 425931 & 435473 \\
\hline 0.30 & 248076 & 376379 & 408565 & 413761 \\
\hline 0.35 & 255517 & 371042 & 395671 & 399281 \\
\hline 0.40 & 270274 & 374796 & 393724 & 396128 \\
\hline 0.45 & 262398 & 347110 & 359920 & 361273 \\
\hline 0.50 & 263517 & 332258 & 340914 & 341730 \\
\hline 0.60 & 250651 & 288679 & 291539 & 291716 \\
\hline $\boldsymbol{\varepsilon}$ & $\mathbf{Q}_{\text {stored }}[\mathbf{k J}]$ & $\mathbf{Q}_{\text {stored }}[\mathbf{k J}]$ & $\mathbf{Q}_{\text {stored }}[\mathbf{k J}]$ & $\mathbf{Q}_{\text {stored }}[\mathbf{k J}]$ \\
\hline 0.20 & $\mathbf{1 8 0 0 0} \mathbf{s}$ & $\mathbf{2 1 6 0 0} \mathbf{s}$ & $\mathbf{2 5 2 0 0} \mathbf{s}$ & $\mathbf{2 8 8 0 0} \mathbf{s}$ \\
\hline 0.30 & 437005 & 437213 & 437237 & 437240 \\
\hline 0.35 & 314430 & 414505 & 414512 & 414513 \\
\hline 0.40 & 396377 & 396399 & 396401 & 399792 \\
\hline 0.45 & 361405 & 361416 & 361417 & 361417 \\
\hline 0.50 & 341794 & 341799 & 341799 & 341799 \\
\hline 0.60 & 291725 & 291725 & 291725 & 291725 \\
\hline
\end{tabular}




\section{Conclusions}

A numerical investigation on thermal energy storage at high temperature was carried out. The storage is a component of a high temperature $\left(>800^{\circ} \mathrm{C}\right)$ thermal solar plant. The thermal storage was cylindrical, the storage medium was a solid and it was modelled as a porous medium. The transient regime analysis was accomplished in the heating phase of the thermal storage with different mass velocity and porosity values.

Results showed that, for the considered parameter values, thermal saturation of the TES was attained after eight hours for all considered porosity values and the larger the mass velocity the lower the saturation time. For an assigned mass velocity value the larger the porosity the higher the stored thermal energy at initial time. After the inversion time the trend is the opposite, i.e., the larger the porosity the lower the maximum storage thermal energy, $\mathrm{Q}_{\max }$. However, the best value of porosity to reach about $0.85 \mathrm{Q}_{\max }$ in the lowest time is 0.40 for the lowest considered $\mathrm{G}$ values and 0.20 for the highest considered $\mathrm{G}$ values.

\section{Acknowledgement}

This work was supported by MIUR with Articolo 12 D. M. 593/2000 Grandi Laboratori "EliosLab".

\section{Nomenclature}

\begin{tabular}{|c|c|c|c|}
\hline c & specific heat, $\mathrm{J} \mathrm{kg}^{-1} \mathrm{~K}^{-1}$ & \multicolumn{2}{|c|}{ Greek symbols } \\
\hline $\mathrm{C}_{2}$ & $\begin{array}{l}\text { inertial resistance } \\
\text { coefficient, } \mathrm{m}^{-1}\end{array}$ & $\alpha^{-1}$ & viscous coefficient, $\mathrm{m}^{-2}$ \\
\hline G & mass velocity, $\mathrm{kg} \mathrm{m}^{-2} \mathrm{~s}^{-1}$ & $\varepsilon$ & porosity \\
\hline $\mathrm{k}$ & $\begin{array}{l}\text { thermal conductivity, } \\
\mathrm{Wm}^{-1} \mathrm{~K}^{-1}\end{array}$ & \multicolumn{2}{|c|}{ Subscript } \\
\hline$\dot{m}$ & mass flow rate, $\mathrm{kg} \mathrm{s}^{-1}$ & $\mathrm{amb}$ & ambient \\
\hline Q & thermal energy, $\mathrm{J}$ & eff & effective \\
\hline $\mathrm{Q}_{\text {stored }}$ & stored thermal energy, $\mathrm{J}$ & & \\
\hline \multirow[t]{2}{*}{$\mathrm{S}$} & free flow area of module & $\mathrm{f}$ & fluid \\
\hline & storage cross section, $\mathrm{m}^{2}$ & $\mathrm{i}$ & initial \\
\hline $\mathrm{t}$ & time, $\mathrm{s}$ & in & entering \\
\hline $\mathrm{T}$ & temperature, $\mathrm{K}$ & $\max$ & maximum value \\
\hline V & volume, $\mathrm{m}^{3}$ & $\mathrm{~s}$ & solid \\
\hline
\end{tabular}

\section{References}

[1] Dincer, I. \& Rosen, M., Thermal energy storage: System and application, John Wiley \& Sons, 2002. 
[2] Paksoy, H. Ö., Thermal energy storage for sustainable energy consumption: Fundamentals, Case studies and design, Springer, 2007.

[3] Beckmann, G. \& Gilli, P.V., Thermal energy storage: Basics, Design, Applications to power generation and heat supply, Springer, 2002.

[4] Sharma, A., Tyagi, V.V., Chen, C.R. \& Buddhi, D., Review on thermal energy storage with phase change materials and applications, Renewable and Sustainable Energy Reviews, 13, pp. 318-345, 2009.

[5] Angelino, G. \& Invernizzi, C., Binary conversion cycles for concentrating solar power technology, Solar Energy, 82 (7), pp. 637-647, 2008.

[6] Vaivudh, S., Rakwichian, W. \& Chindaruksa, S., Heat transfer of high thermal energy storage with heat exchanger for solar trough power plant, Energy Conversion and Management, 49, pp. 3311-3317, 2008.

[7] Salomoni, V. A., Majorana, C. E., Giannuzzi, G. M. \& Miliozzi, A., Thermal-fluid flow within innovative heat storage concrete systems for solar power plants, International Journal of Numerical Methods for Heat and Fluid Flow, 18 (7-8), pp. 969-999, 2008.

[8] Cautier, J. P. \& Farber, E. A., Two applications of a numerical approach of heat transfer process within rock beds, Solar Energy, 29, pp.451-462, 1982.

[9] Barker, J. J., Heat transfer in packed beds, Industrial \& Engineering Chemistry, 57, pp. 43-51, 1965.

[10] Balakrishnan, A., Pei, R. \& David, C. T., Heat transfer in packed bed systems - a critical review, Industrial and Engineering Chemistry, Process Design and Development, 18, pp.30-40, 1979.

[11] Ismail, K. A. R. \& Stuginsky, R. Jr., A parametric study on possible fixed bed models for $\mathrm{pcm}$ and sensible heat storage, Applied Thermal Engineering, 19, pp.757-788, 1999.

[12] Singh, R., Saini R. P. \& Saini, J. S., Nusselt number and friction factor correlations for packed bed solar energy storage system having large sized elements of different shapes, Solar Energy, 80, pp.760-771, 2006.

[13] Schumann, T. E. W., Heat transfer: a liquid flowing through a porous prism, J. Franklin Inst., 208, pp.405-416, 1929.

[14] Furnas, C. G., Heat transfer from a gas stream to a bed of broken solids II, Industrial \& Engineering Chemistry, 22, pp. 721-731, 1930.

[15] Handley, D. \& Heggs, P. J., The effect of thermal conductivity of the packing material on transient heat transfer in a fixed bed, International Journal of Heat and Mass Transfer, 12, pp.549-570, 1969.

[16] Gross, D. J., Hickox, C. E. \& Hackett, C. E., Numerical simulation of dual-media thermal energy storage systems, Trans. ASME, Journal of Solar Energy Engineering, 102, pp.287-297, 1980.

[17] Beasley, D. E. \& Clark, J. A., Transient response of a packed bed for thermal energy storage, International Journal of Heat and Mass Transfer, 27, pp.1659-1699, 1984.

[18] Gunn, D. J., Axial and radial dispersion in fixed beds, Chemical Engineering Science, 42, pp. 363-373, 1987. 
[19] Gunn, D. J., Ahmed M. M. \& Sabri, M. N., Radial heat transfer to fixed beds of particles, Chemical Engineering Science, 42, pp.2163-2171, 1987.

[20] Vortmeyer, D. \& Schaefer, R. J., Equivalence of one and two-phase models for heat transfer processes in packed beds: one dimensional theory, Chemical Engineering Science, 29, pp. 485-491, 1974.

[21] Sowell, E. F. \&. Curry, R. L., A convolution model of the rock bed thermal storage units, Solar Energy, 24, pp.441-449, 1980.

[22] Torab, H. \& Beasley, D. E., Optimization of packed bed thermal energy storage unit, Journal of Solar Energy Engineering, 109 (3), pp.170-175, 1987.

[23] Sagara, K. \& Nakahara, N., Thermal performance and pressure drop of packed beds with large storage materials, Solar Energy, 47 (3), pp.157-163, 1991.

[24] Laing, D., Steinmann, W. D., Tamme, R. \& Richter, C., Solid media thermal storage for parabolic trough power plants, Solar Energy, 80 (10), pp. 1283-1289, 1980.

[25] Navarrete-González, J. J., Cervantes-de Gortari, J. G. \& Torres-Reyes, E. Exergy analysis of a rock bed thermal storage system, International Journal of Exergy, 5 (1), pp. 18-30, 2008.

[26] Arias, D. A., McMahan, A. C. \& Klein, S. A., Sensitivity of long-term performance simulations of solar energy systems to the degree of stratification in the thermal storage unit, International Journal of Energy Research, 32 (3), pp. 242-254, 2008.

[27] Fluent Incorporated, Fluent 6.2, User Manual, Lebanon, NH, 2005. 